\title{
Adapting MAIN to Arabic
}

\author{
Ute Bohnacker* \\ Uppsala University \\ Rima Haddad \\ Uppsala University
}

This paper provides some brief background information on the Arabic language and describes how MAIN (Multilingual Assessment Instrument for Narratives) was adapted to several varieties of Arabic.

\section{$1 \quad$ Introduction}

This chapter first provides some background information on Arabic, and then describes the process of how the Arabic versions of the Multilingual Assessment Instrument for Narratives $(\mathrm{MAIN})^{1}$ were developed and how they have been used. There are few other standardised language elicitation and assessment instruments that can be used with Arabic-speaking children, and, as far as we know, none in the domain of narratives.

\section{A very short description of the Arabic language}

Arabic is a Semitic language and is thus related to Aramaic and Hebrew (Semitic languages belong to the Afro-Asiatic language family). Arabic is spoken in large parts of the world, particularly in the Middle East and Northern Africa. Due to a history of migration, Arabic is nowadays also spoken by a considerable number of immigrants and their descendants in Europe and other regions of the world.

\footnotetext{
* Acknowledgment: Ute Bohnacker's contribution to this work was partly supported by funding from the Swedish Research Council (Grant VR 421-2013-1309).

${ }^{1}$ MAIN is part of Language Impairment Testing in Multilingual Settings (LITMUS). LITMUS is a battery of tests that have been developed in connection with the COST Action IS0804 Language Impairment in a Multilingual Society: Linguistic Patterns and the Road to Assessment (2009-2013).
} 
Arabic has the status of an official language in more than twenty countries, including Algeria, Bahrain, Egypt, Iraq, Jordan, Kuwait, Lebanon, Libya, Morocco, Mauretania, Oman, Palestine, Qatar, Saudi Arabia, Somalia, Sudan, Syria, Tunisia, United Arab Emirates and Yemen. Arabic is also used as a semi- or second official language in countries such as Chad, Comoros, Djibouti, Eritrea, Israel, Tanzania and Western Sahara. Moreover, Classical Arabic is the language of the Koran and the liturgical language of Islam.

Arabic comprises many different vernaculars, i.e. spoken varieties or 'dialects', as well as the standard written variety, Modern Standard Arabic (MSA, fuṣha). These Arabic varieties differ considerably from each other, and they are not always mutually intelligible, especially those that are geographically and/or historically distant. Major dialect groups include Egyptian, Gulf Arabic, Iraqi, Levantine, Maghrebi, Sudanese and Yemeni Arabic. The spoken varieties do not only differ from each other, but also diverge considerably from MSA; this holds for all domains of language (phonology, morphology, syntax, the lexicon, and discourse pragmatics). Diglossia is commonplace, i.e. the existence of two or more different varieties side by side that are used for different functions and situations (Ferguson 1959:232-234; Altoma 1969; Bassiouney 2009:10). Speakers of Arabic generally use their dialect for oral communication, and MSA for reading and writing. There may also be a continuum from the colloquial local dialect to a regional variety and to more formal MSA (Badawi 1973).

Children growing up with Arabic are first exposed to and acquire their local or regional Arabic variety ('dialect') from their parents, family and community. This variety is used in daily oral communication and activities. By contrast, MSA is generally taught through formal education at school. MSA is considered to have high status and is mainly used in literary contexts and formal situations, e.g. news broadcasts on radio and television, public authorities, newspapers, journals, books, street signs, advertisements, and formal written communication, but not so much in daily informal communication. MSA is therefore not considered to be the mother tongue of Arabic-speaking children, but rather a second language. Native speakers of Arabic are speakers of one of the Arabic varieties that they were exposed to and that they acquired first in childhood (Holes 2004:3). It should be said, however, that many Arabic-speaking children nowadays are not only exposed to one local or regional variety of Arabic. Due to the influence of television and other media as well as the effects of globalisation and migration, children may come in contact with other dialects and MSA from an early age. If such contact is extensive, they may blend words and features from other dialects or MSA into their mother-tongue dialect. This of course also occurs in adult speakers of Arabic. They are often able to adapt their spoken variety of Arabic to the circumstances, e.g. by temporarily or more permanently eliminating local dialectal features in favour of more regional or MSA ones, in order to help communication with Arabic speakers of other varieties, or for reasons of prestige. Conversely, colloquial dialectal features are sometimes mixed into MSA to achieve certain effects, such as authenticity or group identification.

MSA is written with the Arabic alphabet. For the dialects, there are no standardised writing conventions. The Latin alphabet is used for writing when the Arabic alphabet is unavailable or difficult to use for technical reasons, such as in emails or mobile text messages. Such Latin spelling (ASCII) of Arabic is used without any standardised orthography. 
Arabic is a richly inflectional language. Here we can only give a bare-bones summary; for a comprehensive description of the structure of the Arabic language, we refer the reader to Arabic reference grammars, including those of the Arabic dialects (e.g. Erwin 1963; Wallace 1963; Cowell 2005; Rice \& Sa'id 2005; Badawi, Carter \& Gully 2016).

Arabic words generally consist of a consonantal root which carries meaning (similarly to a lexical root in Indo-European languages, for instance), combined with a vowel pattern for word formation. The consonantal root is a number of consonants, often three or four (the socalled radicals). The vowel pattern is a combination of short and/or long vowels that are interspersed with the consonantal root. Arabic vowel patterns function similarly to derivational morphemes in Indo-European languages. Grammatical information in the verbal and the nominal domain is mainly encoded via inflectional affixes (e.g. for person, number or verbal aspect). There are two genders (masculine and feminine), and three numbers (singular, dual, and plural). Definiteness is marked by an enclitic article. Case marking as found in MSA is generally not realised in the Arabic dialects. Verbs have two aspectual base forms, imperfective and perfective. Prepositions are used. The construct state, or constructed genitive (idāfa), a juxtaposition of two nouns (or noun phrases), is frequently used to encode possession and related semantic functions. Pro-drop is widespread; subject features are encoded on the verb. The basic word order of verbal clauses in MSA and a number of Arabic dialects is considered to be VSO (verb-subject-object), though SVO (subject-verb-object) is also common (Dryer 2013), and nominal clauses tend to be subject-initial. Certain dialects, such as Iraqi and Egyptian varieties, may be considered to have SVO as the default word order (Barth Magnus \& Tawaefi 1989).

\section{Adapting MAIN to Arabic}

\subsection{Early developments and Standard Arabic}

The Multilingual Assessment Instrument for Narratives, MAIN (Gagarina, Klop, Kunnari, Tantele, Välimaa, Balčiūnienė, Bohnacker \& Walters 2012) was first launched in June 2013, after several years of intensive theory development and material construction by Working Group 2 "Narrative and Discourse" of the EU COST Action IS0804 (2009-2013). The instrument was at first developed and piloted for 15 languages, but during the last few months of the Action, some more language versions were added.

One of the versions that was created at this late stage, i.e. without previous piloting, was the Standard Arabic version. Hadil Karawani, a linguist and native speaker of Palestinian Arabic, translated the English version of the MAIN into Standard Arabic in May 2013, and it was included in ZASPiL 56 (Gagarina et al. 2012) for the launch of MAIN for 26 language versions in June 2013. Karawani's Standard Arabic version was not piloted, but simply translated. Due to the diglossic situation of Arabic, as outlined in the previous section, it would in fact have been difficult, if not futile, to try out the translated Standard Arabic version on Arabic-speaking children, since they do not grow up with Standard Arabic, but with 
Arabic dialects as their mother tongue. Unsurprisingly, there was little demand for the Standard Arabic version of MAIN in the years following the end of the Action. No Arabicspeaking member or researcher working with Arabic-speaking populations had been active in the "Narrative and Discourse" working group during the COST Action.

\subsection{Piloting MAIN for spoken Arabic varieties, starting with Baghdadi Iraqi Arabic}

A few years later, in 2014, interest increased concerning MAIN and Arabic, but this time Arabic vernaculars were in focus. As part of a large-scale research project, BiLI-TAS, ${ }^{2}$ on the language development of Arabic-speaking and Turkish-speaking bilingual children growing up in Sweden, Ute Bohnacker at the Department of Linguistics and Philology at Uppsala University oversaw the development and piloting of MAIN for several varieties of Arabic commonly spoken in Sweden. Due to Sweden's particular history of migration, Iraqi and Levantine varieties (e.g. Lebanese, Syrian, Palestinian) predominate in adult and child speakers of Arabic in Sweden today. We therefore focused on these varieties.

First off was the development of a pilot version for (Baghdadi) Iraqi Arabic. As part of an M.A. thesis project, Mohaned Ridha translated MAIN into Baghdadi Iraqi Arabic in 2014/2015, on the basis of Karawani's (2012/2013) Standard Arabic version and the English and Swedish versions. Ridha is a native speaker of Baghdadi Iraqi Arabic and an interpreter; his translation was checked by Anette Månsson (senior lecturer in Semitic languages, Uppsala University), and changes were made after discussions with Ute Bohnacker. As there is diglossia in Arabic, where commonly only MSA is used for writing, a diglossic document was created: Those parts of MAIN that involved direct language use of the experimenter to the child (i.e. giving instructions, prompting, asking comprehension questions, and story scripts) or language by the child (i.e. story production, answers to comprehension questions) were rendered in the Iraqi dialect. All other parts of the MAIN text (e.g. headings, protocols, explanations, background information) were kept in MSA.

Care had to be taken to choose words and phrases that felt and sounded natural in colloquial Iraqi Arabic, rather than a strict direct translation of an English term. This particularly concerned the dialectal rendering of internal state terms in the MAIN comprehension questions, such as translations of adjectives like 'disappointed' or 'fine/good'. Sometimes there was no good direct translation, or only a low-frequency, literary, formal or stilted one; in such cases, a paraphrase or circumlocution had to be chosen. For best effect, we translated and back-translated not only between English and Arabic, but also between Arabic and Swedish. This involved several rounds of discussion. When Ridha tried out his translation with a few Iraqi Arabic-speaking children, some problems were noticed. For instance, in the Baby Goats story, the translation of the English basic-level term bird (to refer to the black crow) as an Iraqi Arabic basic-level term asfor 'bird' or ter 'bird' did not always work. Some children preferred a more specific term for this character, such as gharab/ghorab 'raven' or

\footnotetext{
${ }^{2}$ BiLI-TAS is an acronym for Bilingualism, Language Impairment, Turkish, $\underline{\text { Arabic, }}$ Swedish, a project funded by the Swedish Research Council (Grant VR 421-2013-1309).
} 
niser/nisre 'eagle, eagle-type predator'. Attempts were made to be inclusive and allow for a number of different lexical choices by the children, since they may have been exposed to other Arabic dialects as well, Iraqi or otherwise.

In March and April 2015, Ridha used the Iraqi Arabic version of MAIN to collect audio- and video recorded data from 12 L1-Iraqi Arabic/L2-Swedish children age 5;3-8;2 growing up in Malmö (Southern Sweden). Every child told two MAIN stories in Arabic and answered comprehension questions. Ridha did not investigate narrative macrostructure or comprehension in the children; he simply used MAIN to elicit comparable language production data from 12 children. This worked well.

A potential problem was the default orientation of the MAIN pictures from left to right. 10 of the 12 bilingual Iraqi Arabic children started to fold out and tell the stories from left to right, probably because they were accustomed to this orientation from Swedish picture books. However, two of the children wanted to begin from right to left, which corresponds to the reading direction in Arabic. Thus, the direction in which the MAIN pictures are administered might require some further thought.

For his M.A. thesis (Ridha 2015, unpublished), Ridha analysed the recordings with regard to code-mixing and transfer phenomena, and transcribed some extracts of the narratives in Arabic script. As dialectal transcriptions with the Arabic script proved unsatisfactory, the data of all 12 Iraqi Arabic children was later (in 2016) carefully transcribed anew by Zeinab Shareef, a speech-language pathologist and native speaker of Iraqi Arabic, but this time using the Latin alphabet. All utterances were translated. The transcripts were studied for a number of aspects, including how well the prompting and comprehension questions had worked, children's use of progressive aspect marking, as well as referent introduction and maintenance.

\subsection{Adapting MAIN to Lebanese, Palestinian, Syrian and Iraqi Arabic}

In 2016 and early 2017, in preparation of large-scale data collection from bilingual children speaking Iraqi and Levantine dialects in Sweden, Arabic versions of MAIN were developed for Lebanese, Palestinian, Syrian and Iraqi by Rima Haddad, a member of the Uppsala University BiLITAS research team. For each of the dialects, the adaptation was carried out in consultation with several native-speaker informants, including Semitic dialectology experts. Due to the diglossic situation, only those parts of MAIN that involved direct language by the experimenter to the child (i.e. giving instructions, prompting, asking comprehension questions) were rendered in the dialect; other parts of the MAIN text were again kept in MSA.

First, a Lebanese pilot version was developed. Rima Haddad, a native speaker of Lebanese Arabic, translated it from the English and Swedish versions. Three native speakers of Lebanese Arabic made separate translations of the English and MSA versions. Having compared, discussed and back-translated these versions, a consensus was reached. In order to find the best wording for certain MAIN comprehension questions (e.g. D8, D9, D10) that were particularly tricky to translate, ten native speakers of Lebanese Arabic were consulted. 
For the Syrian, Palestinian and Iraqi versions, informants separately studied the MAIN picture sequences and then translated the comprehension questions from the English, Swedish and MSA versions into their variety of Arabic. The informants also had the possibility to look at the Lebanese translation as an example. Care was taken to recruit native-speaker informants from different regions, e.g. for Syrian Arabic, they came from different regions in Syria (Damascus and Aleppo). As a result, they gave us, at rare times, two possible correct versions of the translation. Such differences were noted and discussed with the informants in person. A typical response then was: "Yes, that can also be said, but I usually say it this way." Informants were also consulted on how best to word the instructions and prompts for 4- to 8year-old children. (These wordings were later piloted with children, see below.) For the Palestinian version, Rima Haddad worked closely with two informants: Sara Kohail, a guest PhD student at the Uppsala Department of Linguistics and Philology and native speaker of the Gaza dialect, and Hadil Karawani at the Leibniz-ZAS, who speaks a northern Palestinian dialect.

A particular challenge were the Iraqi dialects, which differ considerably from the Levantine varieties, and moreover exhibit much regional variation in themselves. It was decided to create two Iraqi Arabic versions, one for the northern Iraqi Mosul dialect, and one geared to the central dialects spoken around Baghdad and Najaf. Ridha's 2015 Baghdadi Iraqi Arabic version was developed further with the help of Zeinab Shareef, a bilingual speechlanguage pathologist who speaks the Najaf dialect (which is different but still comparatively close to Baghdadi). Alternative wordings of questions and prompts were added, and the tense/aspect marking of certain verbs was amended. Overall, these changes were relatively minor. Shareef also recorded audio files in her dialect with instructions and prompts for the child to train experimenters whose native dialect was not Iraqi Arabic. Ridha and Shareef's version was then used with Iraqi Arabic children in Sweden, but during piloting we observed that it worked less well with children speaking northern Iraqi varieties, such as the Mosul dialect. Rima Haddad therefore developed a separate Mosul dialect version, where the lexicon and syntax were amended based on her speaker observations. (At the time, Rima Haddad was in close contact with native-speaker informants from Mosul, as she was developing a dialectal version of a vocabulary task.)

Since we had encountered some problems with using the default left-to-right fold-out and reading direction of the MAIN pictures with Iraqi Arabic children (Ridha 2015), Haddad reoriented the pictures for all four MAIN stories right-to-left. This way, they conformed to the reading and writing direction for Arabic and the way books and Arabic children's picture books are printed. We have since used the right-to-left orientation in all subsequent work with Arabic-speaking children and MAIN. Since we work with children growing up in Sweden who are also exposed to Swedish (picture) books with a left-to-right reading direction, we sometimes add when instructing the child: "The story starts from here [point to the picture on the right] from right to left, since the story is in Arabic".

Then, in early 2017, Haddad piloted the Arabic dialect versions with children in several cities in Southern Sweden (Malmö and Landskrona) and Central Sweden (Uppsala and Stockholm). 
Some of the prompts and comprehension questions did not work satisfactorily at first. For instance, many children failed to understand the Arabic renderings of the MAIN comprehension questions that targeted internal states and queried feelings of story characters. Our first renderings of these questions had been direct translations from English (e.g. How does the $X$ feel? Why do you think that the $X$ is feeling bad/scared/hungry/disappointed etc.?). However, in Arabic these questions did not seem to work well. We experimented quite a bit with alternative Arabic wordings for comprehension questions that would still be equivalent to the English questions - and elicit the desired answers. For instance, the D8 question in the Cat story Imagine that the boy sees the cat. > How would the boy feel? was in the end rendered as follows in Lebanese Arabic: txeyal ennu eș-șabi šef el-bsayne, šu ken hass eṣsabi? تخيّل انّو الصبي شاف البسينة، >> شو كان حس الصبي؛ (literally: imagine that the boy

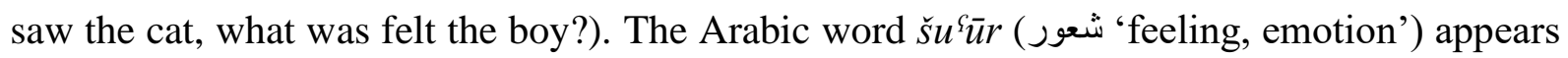
not to be easily understood by young children, and some of our adult informants also considered it to be a more literary word or more typical of MSA (informants were not in full agreement here though). We then replaced šu'ūr with ihsses (إحساس 'feeling'), which by many (but not all) informants was considered to be a synonym, more dialectal, more frequent and/or easier for children.

Care had to be taken to choose words and phrases that felt natural in the Arabic dialects and were understood by the children. Here we translated and back-translated between the English and Swedish versions of MAIN and Arabic, as well as between Arabic dialects, and continually consulted with native-speaker informants. We also profited from Ute Bohnacker's experience in having been involved in the development of MAIN and the adaptation and piloting of a number of other language versions. Rima Haddad drew up lists of alternative prompts and question wordings. For instance, in the Cat story, comprehension question D2 How does the cat feel? is rendered in four different ways in the four dialect versions, see Table 1.

Table 1: Dialectal variation in the wording of MAIN comprehension question D2 (Cat story).

\begin{tabular}{|c|c|}
\hline Lebanese & كيف حاسيّة البسينة؟ \\
\hline Palestinian (Gaza) & 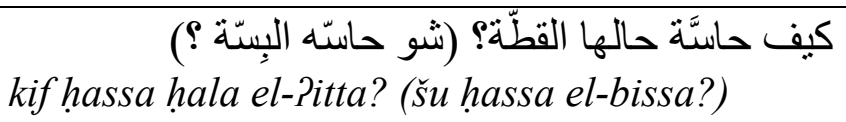 \\
\hline Syrian (Damaskus) & 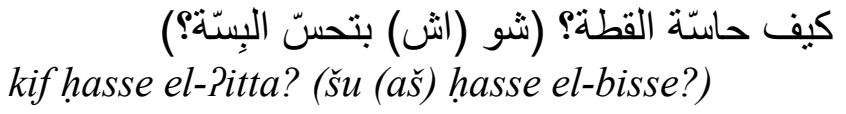 \\
\hline Iraqi (Najaf) & 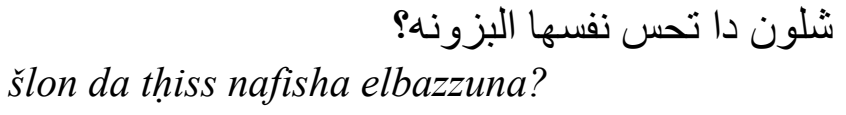 \\
\hline & 'How does the cat feel?' \\
\hline
\end{tabular}

Due to the complex diglossic situation where children may have been exposed to different Arabic dialects, attention needed not only to be paid to the wording of instructions, prompts and comprehension questions, but also to the child's lexical choice when referring to a story character. For instance, children referred to the cat in the Baby Birds and the Cat stories with 
many different Arabic terms, all denoting 'cat', e.g. bezzone, bisse, bsayne, qitta, hirra. The child's choice of term should then also be used by the experimenter when asking questions about the cat. (Recall that similar issues also had arisen in Ridha's piloting of his 2015 Baghdadi Iraqi Arabic version concerning the word 'bird', see previous section.)

In 2017-2019, MAIN data were collected with Haddad's amended Lebanese, Palestinian, Syrian and Iraqi versions of MAIN from more than 125 Arabic-speaking children growing up in Eastern Central Sweden. Children told two stories each in Arabic and answered the comprehension questions. MAIN was administered by Rima Haddad and three trained Arabic native-speaker research assistants. Experimenters accommodated to the child and worded their instructions, prompts and comprehension questions to match the dialectal variety of the child as much as possible (the children spoke Syrian, Palestinian, Iraqi and Lebanese dialects). When the child showed signs of not understanding, synonyms from other dialects were used. This generally worked well.

We also administered our existing MAIN versions to a handful of children speaking other Arabic varieties (other than Levantine and Iraqi dialects), such as Egyptian, Sudanese or Maghrebi. For Egyptian, this worked relatively well, as the experimenter could accommodate to the child during testing, so that the child understood the prompts, performed the narrative tasks and answered the comprehension questions. However, for children speaking Sudanese and Maghrebi, this worked badly. Despite the experimenter's best efforts, child and experimenter misunderstood each other, and the resulting data cannot be taken to be representative of the narrative abilities of the child. We had to exclude such data from our dataset. Thus, we do not recommend that our Lebanese, Palestinian, Syrian and Iraqi versions of MAIN be used with children of other dialects of Arabic, especially dialects that are very different (such as Sudanese, Maghrebi, Yemeni etc.); rather, versions for these other dialects would need to be developed and piloted before use.

Our MAIN data from more than 100 Arabic-speaking children in Sweden (Syrian, Palestinian, Iraqi, Lebanese, Egyptian dialects) have recently been transcribed by Rima Haddad and Pascale Wehbe, using the Latin alphabet and a transliteration system that unifies word identification procedures and word counts regardless of the Arabic variety that the children speak. The Arabic narrative production and comprehension data are currently being analysed for a number of aspects, including macrostructure and referent introduction, as part of the BiLI-TAS research project at Uppsala University.

The Lebanese, Palestinian, Syrian and Iraqi Arabic versions of MAIN developed at Uppsala University during 2015-2017 have not been made publicly available earlier. It was agreed that any such publication should not precede but rather follow the launch of the Revised version of MAIN (Gagarina, Klop, Kunnari, Tantele, Välimaa, Bohnacker \& Walters 2019). Whilst work on the Revised version was ongoing, a number of researchers working on Arabic got in touch with us about MAIN. They asked about Arabic dialects, and asked about the existing Standard Arabic version (Karawani 2015) and how it could be used with Arabicspeaking children (our answer was that it cannot). Researchers also wanted to get access to our dialect versions or were planning to create Arabic dialect versions of their own. We tried 
to bundle these efforts and steer them towards cooperation, in order to stem the proliferation of alternative versions.

Instead of new and different unofficial Arabic versions of MAIN continuously being translated 'on the fly', we feel that is important that dialectal versions are carefully constructed and piloted before use, following the Guidelines for adapting MAIN to other languages (Bohnacker \& Gagarina 2019). Preferably, this should be done in cooperation with experienced MAIN researchers, such as a core author of the Revised version of MAIN. Otherwise there is, in our experience, a risk that children may be unduly advantaged or disadvantaged over others, depending on which version is used, which jeopardises the comparability of results.

We have shared our Arabic MAIN versions with research groups in Beirut (Lebanon), Oldenburg and Flensburg (Germany) and entered into cooperation with them. For instance, concerning the Lebanese Arabic version, in 2017 we worked with Rachel Fiani from Saint Joseph University (USJ, Beirut) who was developing a Lebanese version for the Baby Birds story and piloted it with 18 bilingual children in Lebanon. We cooperated to harmonise the wording of instructions and comprehension questions with our Uppsala Lebanese Arabic version. Another example of cooperation concerns the Palestinian and Syrian Arabic versions of MAIN. Here we worked with Lina Abed Ibrahim at Oldenburg University in 2017, who, amongst other things, had translated the materials for the Cat story into Palestinian, on the basis of the English and German versions. When Abed Ibrahim piloted her translation with Arabic-speaking children in Germany, she ran into similar problems as we had done in Sweden, regarding the wording of internal-state comprehension questions that queried the feelings of story characters. Abed Ibrahim found that some children did not understand the Arabic word for 'feeling' (شعور). Having compared her translation with our Uppsala versions, particularly the Lebanese one, it was decided to paraphrase 'feeling' in Palestinian as we had done for Lebanese. Abed Ibrahim also used our Syrian Arabic version in Germany. Abed Ibrahim and Haddad cooperated in 2019, discussed dialectal formulations, and met to harmonise some of the scoring of narrative macrostructure and answers to comprehension questions in our Arabic MAIN data in Sweden and Germany.

In November 2019, the Revised version of MAIN was published for English, German, Russian, Swedish, and Turkish for the bilingual population in Sweden (ZASPiL 63, Gagarina et al. 2019). These revisions were the result of intensive collaboration between Ute Bohnacker's research group at Uppsala University and Research Area 2 at the Leibniz-ZAS, led by Natalia Gagarina. They include improved guidelines, elicitation and scoring procedures for MAIN.

Rima Haddad and the Uppsala research team have adapted the Lebanese, Palestinian, Syrian and Iraqi versions to this Revised version of MAIN (2019). The revised Arabic versions are part of the present issue, ZASPiL 64. 


\section{References}

Altoma, S. (1969). The problem of diglossia in Arabic: A comparative study of classical Arabic and Iraqi Arabic. Cambridge, MA: Harvard University Press.

Badawi, E. (1973). Mustawayāt al-'arabiyya al-mu'āṣira fi Miṣr: baḥth fì 'alāqat al-lughah bi-al-ḥad̄ârah. Cairo: Dār al-ma'ārif.

Badawi, E., Carter, M. G., \& Gully, A. (2016). Modern written Arabic: A comprehensive grammar. New York: Routledge.

Barth Magnus, G., \& Tawaefi, L. (1989). Arabiska: En kontrastiv beskrivning. Stockholm: Skriptor.

Bassiouney, R. (2009). Arabic sociolinguistics: Topics in diglossia, gender, identity, and politics. Edinburgh: Edinburgh University Press.

Bohnacker, U., \& Gagarina, N. (2019). Background on MAIN - Revised, how to use it and adapt it to other languages. ZAS Papers in Linguistics, 63, iv-xii.

Campbell, G., \& King, G. (2012). Compendium of the world's languages. $3^{\text {rd }}$ ed. London \& New York: Routledge.

Cowell, M. W. (2005). A reference grammar of Syrian Arabic. Washington, DC: Georgetown University Press.

Dryer, M. (2013). Order of subject, object and verb. In: M. S. Dryer \& M. Haspelmath (Eds.), The world atlas of language structures online. http://wals.info/chapter/81.

Erwin, W. (1963). A short reference grammar of Iraqi Arabic. Washington, DC: Georgetown University Press.

Ferguson, C. (1959). Diglossia. Word 15, 325-340.

Gagarina, N., Klop, D., Kunnari, S., Tantele, K., Välimaa, T., Balčiūnienė, I., Bohnacker, U., \& Walters, J. (2012). Multilingual Assessment Instrument for Narratives (MAIN). ZAS Papers in Linguistics, 56.

Gagarina, N., Klop, D., Kunnari, S., Tantele, K., Välimaa, T., Bohnacker, U., \& Walters, J. (2019). MAIN: Multilingual Assessment Instrument for Narratives - Revised. ZAS Papers in Linguistics, 63.

Holes, C. (2004). Modern Arabic: Structures, functions, and varieties. Washington, DC: Georgetown University Press.

Rice, F. A., \& Sa'id, M. F. (2005). Eastern Arabic: An introduction to Palestinian Arabic. Washington, DC: Georgetown University Press.

Ridha, M. (2015). Crosslinguistic influence in the Arabic of Iraqi Arabic-Swedish bilingual children (5-7) in Sweden. Unpublished M.A. thesis, Dept. of Linguistics and Philology, Uppsala University.

Ryding, K. (2005). A reference grammar of Modern Standard Arabic. Cambridge: Cambridge University Press.

Wallace, E. (1963). A short reference grammar of Iraqi Arabic. Washington, DC: Georgetown University Press. 